\title{
Study on the Problems and Countermeasures of Foreign Affairs Police Training
}

\author{
Li Guo
}

Jiangxi Police College, Nanchang, Jiangxi, 330103, China

Keywords: foreign police training; problems; countermeasures; research

\begin{abstract}
The problems found in the course of the training of foreign police officers in our country are concentrated in aspects of the incomplete institutional mechanisms, the lack of rationality in curriculum, the relatively outdated content of teaching materials, weak teacher resources, the level of education to be optimized and the unsatisfactory results of follow-up assessment, etc. Therefore, in the process of future development, it is required to correctly recognize the issue of foreign affairs police training, and correctly recognize the deficiencies of foreign affairs police training, and take scientific and rational measures to adopt necessary improvement strategies in light of the actual situation. Based on this, the paper regards the training of foreign police as the key research content, expounds its existing problems, and puts forward effective measures for improvement, hoping they will be helpful.
\end{abstract}

\section{Interpretation of Current Training Issues for Foreign Affairs Police}

\subsection{Incomplete institutional mechanisms}

For now, a training network for foreign police has been formed in the long-term development process of domestic foreign affairs police training, which covers the physical evidence appraisal center of the public security department, and several central and local police colleges and universities and scientific research institutions. However, in the course of practice, the rationality of the police training network has not been effectively implemented, and it has been difficult to fundamentally change the phenomenon of self-government. The orientation of functions, capital investment, institutional setup, the construction of teachers and curriculum still have a long way to go compared to developed countries.

\subsection{Irrational curriculum provision}

Due to the short development time of domestic and foreign affairs police training, the curriculum system lacks systematic and complete features. In particular, prior to training, communication with the recipient country is not in place, and the understanding of the key information content such as the requirements and purpose of the recipient country is not comprehensive during the preparation of the course, so that there are major differences in the trainee's own language ability, professional titles and professional backgrounds. In addition, the setting of the curriculum is not satisfactory, which directly affects the practicality and pertinence of the training of foreign police.

\subsection{Relatively outdated teaching materials}

The contents of training materials for foreign police officers are relatively outdated. From the objective aspect, there are no professional talents. Whereas, subjective analysis still shows that the degree of attention is not up to standard, and that experts and scholars are organized and invited to implement necessary research and preparation instead of using the era level as an entry point, so it is difficult to achieve the development goals of international policing exchanges and collaborations in practice, or to keep up with the development needs of transnational crime prevention and development. It still takes a long time to have a more systematic and complete teaching material mechanism. It is precisely because of the backwardness of the content of the 
teaching materials that the content of the training is so simple that the college is only taught with Chinese culture and policing work status, laws, regulations and business skills. It still does not possess strong operational, theoretical, and adaptability.

\subsection{Weak faculty}

First, the structure of the teaching staff lacks rationality. The number of teachers with higher professional standards is small, the number of teachers studying for doctoral degrees is small, and the number of young professors is not large.

Second, in the teaching staff, the number of first-class professionals is small, and teachers who can participate in foreign police training and teaching are even fewer.

Third, the training time for some training classes is not long, and a large number of course contents will be condensed. There is also a brief summary in the course of lectures, so it is difficult to improve the teachers' own teaching ability and theoretical research ability.

Fourth, some teachers are unable to quickly respond to the academic issues of policing and policing science and technology, and they do not have the ability to deeply and systematically recognize the dynamics of foreign police science development and new developments, which directly affects the quality of scientific research and scientific research work.

\subsection{Education and teaching needs to be optimized}

Currently, foreign police training in Western developed countries has accumulated a great deal of experience and has explored ways that can be adapted to actual combat. However, in China, the training of foreign police officers is only at the initial stage of development. Although the intensity of investment has been increased, there are still large differences between the training bases for actual combat skills and the construction of simulation laboratories in Western countries, and the training methods are too extensive. Simple, the content emphasizes theoretical knowledge and neglects the role of actual combat skills, which leads to a serious impact on the quality of training.

\subsection{Poor tracking evaluation}

In China, there are three deficiencies in the application of foreign affairs police training effects:

First, the ideological cognition is not up to the standard.In the training of foreign police officers, they did not attach great importance to the role of trainees in the use of renewable resources, nor did they correctly recognize the importance of training in foreign police on the basis of strategic height. Therefore, the training of foreign affairs police officers has not achieved long-term and strategic development.

Second, the main body of work is not in place. In the process of implementing the training of foreign police, the organization personnel and management personnel are generally drawn temporarily, and their workload is large. Therefore, the corresponding staff is not arranged to carry out the necessary follow-up assessment for the students after the training project, and lack of follow-up evaluation system as a constraint.

Finally, special funds are insufficient. Since it does not have the special funds for tracking and evaluation, it is difficult to communicate and communicate with the countries under training. Under such circumstances, it is very difficult to actively conduct follow-up evaluations for trainees, and it is difficult to systematically grasp the evaluation results of the training quality of the training students. This will directly affect the effectiveness of training for foreign police.

\section{Specific Measures to Improve the Training of Foreign Affairs Police}

\subsection{Effective innovation of institutional mechanisms}

On the one hand, it is necessary to actively build consensus, that is, the simultaneous development of academic education, on-the-job training, and foreign police training. Among them, in the process of implementing the training of foreign police, the foreign police training should be upgraded to a 
new level and repositioned and recognized. Moreover, educational resources need to be tilted to the field of training for foreign police to further promote the smooth development of foreign police training. This will make the development of the above three more coordinated and synchronized and promote each other by complementing with each other.

On the other hand, build the corresponding platform. Among them, it is necessary to actively build a network of exchange training platforms for foreign police to break through the constraints of time and space, ensure the timely dissemination of information, simplify the convenience of operation, and highlight its exemplary role. To make full use of the advantages of the network communication platform, it is necessary to ensure the beauty of web design, and the richer content, and to achieve extension and innovation.At the same time, it is necessary to build an exchange platform for the annual training of foreign police training. The public security academies and scientific research institutions responsible for the training tasks of foreign affairs police officers shall organize and hold annual meetings every year. The specific topics, locations, time and scale of the annual meetings shall be submitted to the contractor and be determined in a rational manner in light of specific conditions. In addition, an international exchange platform for foreign affairs police training should also be established. We must always follow the concept of opening up to promote reform and development, ensure the effective realization of the goal of exchanges and cooperation in the training of foreign affairs police, and further optimize the degree of internationalization of foreign affairs police training.

\subsection{Reasonable setting of reform course}

In order to better implement the training of foreign affairs police, we must attach great importance to the rationality of the reform of the curriculum. In practice, it is necessary to adapt to the specific needs of the policing work of the recipient countries, and to make the trainees the focus of the foreign affairs police training work. The recipient countries are regarded as important reference objects, and the training of the students' professional abilities is the main goal. In this case, it is necessary to negotiate with the recipient country and set the course based on the actual requirements of the recipient country. In the entire process, it is also necessary to comprehensively consider the country's culture, judicial mechanisms, laws and regulations, and social systems, and arrange internships, visits, and inspections.

On this basis, it is also necessary to formulate appropriate plans scientifically and reasonably. It can be used alone or in conjunction with a number of police academies to build scientific research teams, comprehensively consider the national conditions and specific needs of the recipient countries, and combine the level of students to form a nation-level excellent courses, and ensure that more distinctive police training courses can be developed into international brands and enhance the international influence of domestic and foreign affairs police training in the process of long-term development.

\subsection{Comprehensive construction of foreign police training materials}

Foreign affairs police training materials can focus on the content of curriculum teaching. This is also an important reference basis and material content for teachers' teaching and college learning. Even if the international community has entered the era of information technology, more multimedia videos and networks have been widely used in classroom teaching. However, during the practical process, the training materials for foreign affairs police officers always occupy a basic position in the actual training and teaching process, and they continuously strengthen the authority of the teaching materials.

At this stage, the construction of training materials for foreign affairs police in China has always been in the initial stage of development, which is very different from that of western developed countries. In the course of practice, the foreign police training in China should strengthen cooperation with Western countries, especially in the construction of law enforcement capabilities, and we must strengthen exchanges. In the case of training in foreign affairs police and joint development in the UK, during the course of designing teaching content and curriculum, the 
UK still has reservations and has not imparted purification content. In particular, the core brand training course teaching materials and content have not been mentioned, so there will be issues concerning the overall situation and organization and management of foreign affairs police training in practice. The UK has also taken reasonable arrangements based on comprehensive consideration.

It can be seen that the proper preparation of training materials for foreign affairs police officers is crucial, and it is necessary to learn from the successful experience of textbooks in developed countries. In the process of compiling textbooks, we should abide by the idea of abandonment, adhering to an open and tolerant attitude, and realize the goal of developing China's advanced experience in the developed countries. Combining the specific conditions of the current domestic foreign affairs police training, it is necessary to form a uniform domestic situation for the preparation of foreign affairs police training materials. The advantages of various public security academies and scientific research institutions should be brought into full play. In the long-term practice process, we must ensure that they match the national conditions and Highlight the characteristics of the textbook. Only in this way can it be consistent with the level of the developed countries in the west and obtain the respect and recognition of the countries of the economy and the international community.

\subsection{Effective construction of teaching staff}

In order to further implement the training of foreign affairs police, it is necessary to emphasize the role of teacher team building. Among them, the quality of foreign affairs police training will be directly affected by the quality of teachers themselves, and it is also closely related to the individual teaching ability, level and scientific research ability of teachers. Therefore, an open teacher team with a high theoretical level and relatively rich practical experience should be actively constructed. This is also the soul of training for foreign affairs police. It can fully optimize the core competitiveness of public security schools and advance the comprehensive development of foreign affairs police training.

First is the planning process. Each public security academy and scientific research institution shall formulate a reasonable development plan for the training team of foreign affairs police and appropriately increase investment.

Second is the internal training sessions. The young teachers should be given the necessary encouragement to study master's and doctoral degrees through diversified forms. Meanwhile, it is necessary to regularly organize and arrange excellent teachers to participate in advanced training activities for famous universities at home and abroad, and to train them in the practice department to further enhance their level of learning and teaching.

Next is the external introduction links. The professional development needs of foreign police training science are comprehensively considered, and teachers and academic backbones with more obvious development potential are introduced. On this basis, we should use the era height as an entry point, continuously expand our talents in attracting talents, and adopt ideal environments and policies to attract talents at home and abroad.

The last is the appointment process. In our country, some public security colleges and universities have begun to hire police affairs officers with higher academic tonality and serve as instructors for academic education within the colleges. The actual teaching results are ideal . For a long period of time, these instructors have also been able to impart relevant knowledge to foreign police training students. The duration of appointment has been extended from six months to three years. In addition, you can hire retired police officers to serve as instructors, and combine the actual needs of foreign affairs police training to carry out the appointment.

In the course of practice, we must combine with the development trend of foreign affairs police training to build a database of foreign affairs police trainers in a short period of time. The International Cooperation Bureau of the public security department should require public security institutions to create a national police affairs training teacher staff while maintaining teacher resources. In addition, the establishment of a talent pool for foreign instructors is also very important. Only in this way can teachers share resources and improve training and teaching quality of foreign affairs police and quality service. 


\subsection{Standardized education and teaching}

In order to ensure the smooth development of foreign affairs police training, we should also pay attention to the standardization of education and teaching. In China, the pace of development of foreign affairs police training has been markedly accelerated, but it has not always been able to adapt to the needs of development. Therefore, we must also learn from the advanced experience of western countries. In the process of education and teaching, the important role of loyalty education and practical training is emphasized. On the basis of standardizing education and teaching, the development of training for foreign police is optimized.

\subsection{Implementation of follow-up evaluation}

In the context of the new era, the trend of globalization of the economy has become more pronounced and the level of social information has risen. Therefore, relying only on the police of one country or the means of investigation, it is difficult to prevent and crack down on criminal tasks. To this end, it is necessary to attach importance to the role of foreign affairs police training, follow the basic principles of serving national interests, and communicate and cooperate with foreign affairs police departments, and focus on training trainees to return to the country, actively build a database of trainees, and form a follow-up evaluation mechanism. At the same time, it is also necessary to establish a correlation mechanism with the public security business department to ensure that the counterparty of the public security business can better participate in the training of foreign police.

\section{Conclusion}

To sum up, we conducted research and analysis on the issue of foreign police training in our country, and found that we have a long way to go to the western developed countries. In this case, it is necessary to actively adopt corresponding solutions. Only in this way can we ensure the smooth development of training for foreign police.

\section{References}

[1] Huang Xianying. On Enhancing the Quality of Foreign Affairs Police Training Translators-Taking Affairs Foreign Police Training of Guangxi Police College as an Example, Examination and Assessment, 2016(11):194-195.

[2] Shuang Chunliang. On the Application of "Role Simulation Teaching Model" in Foreign Affairs Police Training, Journal of War Police Academy,2016(5):65-68.

[3] Zhao Xin. Study on the Training of Foreign Affairs Police in the Field of Border Security in Police Colleges in China under the Background of "One Belt and One Road", Chinese Gladiology, 2016(9):130-130.

[4] Hu Youzong, Jiang Guochang. Problems and Countermeasures in the Training of Foreign Affairs Police in China: A Comparative Study of the Training Work of Foreign Affairs Police in China and England, Journal of Public Security, Journal of Zhejiang Police University, 2011(2):97-102.

[5] Wang Jiao. Study on Chinese Teaching in Short-term Foreign Affairs Police Training-Taking Yunnan Police Officer Academy as an Example, Journal of Yunnan Police Officer College,2013(4):43-46. 